\title{
STUDY OF PLATELET COUNT AND LIVER FUNCTION TEST IN PREGNENCY INDUCED HYPERTENSION WOMEN
}

\author{
M. Lavanya ${ }^{1}$, A. Saritha ${ }^{2}$ \\ ${ }_{1}^{1}$ Assistant Professor, Department of Physiology, Santhiram Medical College \& General Hospital, Nandyal. \\ ${ }^{2}$ Assistant Professor, Department of Obstetrics \& Gynaecology, Santhiram Medical College \& General Hospital, Nandyal.
}

\begin{abstract}
The present study was undertaken to evaluate the changes of liver function tests and platelet count in different grades of PIH women. The study group included 90 PIH women divided into 3 groups based on the severity of PIH into 30 mild PIH, 30 preeclampsia and 30 eclampsia. The LFT parameters and platelet count were estimated.
\end{abstract}

\section{CONCLUSIONS}

LFT parameters like AST, ALT, ALP and Platelet estimation can be taken as an early interpretation for assessment of severity of $\mathrm{PIH}$, so that early measures are taken to prevent the maternal and fetal complications.

HOW TO CITE THIS ARTICLE: M. Lavanya, A. Saritha. "Study of Platelet Count and Liver Function Test in Pregnency Induced Hypertension Women." Journal of Evolution of Medical and Dental Sciences 2015; Vol. 4, Issue 95, November 26;

Page: 16090-16093, DOI: $10.14260 /$ jemds/2015/2352.

\section{INTRODUCTION}

Hypertensive disorders in pregnancy is one of the major cause of maternal, perinatal mortality and morbidity.(1) It is one of the commonest medical disorders diagnosed by obstetricians in clinical practice. Pre-eclampsia and eclampsia contribute to death of women every 3 min world-wide. Pregnancy induced hypertension is defined as hypertension that occurs in pregnancy for the first time after 20 weeks of gestation and disappears following delivery.

In PIH placental dysfunction initiate the systemic vasospasm, ischaemia and thrombosis that eventually damage the maternal organs. Thrombus formation or haemorrhage causes liver injury, form hepatocellular necrosis and causes elevation of liver enzymes. Out of all the haematological changes that occur in pre-eclampsia and eclampsia, thrombocytopenia is the most common haematological abnormality found. The degree of thrombocytopenia increases with the severity of disease. Lower the platelet count, greater the maternal and fetal morbidity and mortality.

Early assessment of PIH is necessary to prevent complications like HELLP syndrome (Haemolysis, Elevated Liver Enzymes and Low Platelet Count) and increased maternal and fetal mortality and morbidity.

\section{AIMS AND OBJECTIVES}

- Hypertensive disorders of pregnancy with spectrum of complications like HELLP syndrome- "Haemolysis, Elevated Liver Enzymes, and Low Platelet Count" is one among the leading cause of feto-maternal morbidity and mortality.

Financial or Other, Competing Interest: None.

Submission 05-09-2015, Peer Review 07-09-2015,

Acceptance 28-10-2015, Published 26-11-2015.

Corresponding Author:

Dr. M. Lavanya

Department of Physiology,

Santhiram Medical College,

NH-18, Nandyal-518502.

E-mail:srmcophthal@gmail.com

DOI:10.14260/jemds/2015/2352
- To study and compare the changes in liver function tests in different grades of PIH.

- To study and compare the platelet count changes in different grades of PIH.

- To determine whether the liver function tests and platelet count can be used to assess the severity of PIH.

\section{MATERIALS AND METHODS}

This study was conducted at Santhiram Medical College \& General Hospital, Nandyal for 1-1/2 year from April 2009 to September 2010. Data for the study was collected from patients attending the Department of Obstetrics and Gynecology, Government General Hospital, Kurnool. Consent was obtained from the college ethical committee.

\section{STUDY GROUP}

A prospective clinical study consisting of 90 pregnancy induced hypertensive women, which are divided into 3 groups depending upon the severity.

a) Thirty subjects with mild PIH or hypertension without proteinuria, gestational hypertension or edema.

b) Thirty subjects with pre-eclampsia-hypertension with proteinuria.

c) Thirty subjects with eclampsia-hypertension with convulsions and coma.

International Society for Study of Hypertension in Pregnancy (ISSHP) defined hypertension and proteinuria as:

\section{HYPERTENSION}

a) Diastolic B.P of $110 \mathrm{~mm}$ of $\mathrm{Hg}$ on any one occasion.

b) Diastolic B.P of $90 \mathrm{~mm}$ of $\mathrm{Hg}$ on any 2 or more consecutive occasions $>4$ hrs. apart.

ESTIMATION OF SERUM BILIRUBIN KIT METHOD JENDRASSIK AND GROF METHOD

REAGENTS

Reagent-1

Sodium nitrite $-10 \mathrm{mmol} / \mathrm{lit}$.

Reagent-2

Sulphanilic acid- $23 \mathrm{mmol} / \mathrm{lit}$. 


\section{Reagent-3}

Sodium acetate- $0.9 \mathrm{~mol} / \mathrm{lit}$.

Sodium benzoate- $0.5 \mathrm{~mol} / \mathrm{lit}$.

Caffeine- $0.25 \mathrm{~mol} / \mathrm{lit}$.

\section{Principle}

Bilirubin reacts with diazotized sulfanilic acid to form an azo compound, the colour of which is measured at $546 \mathrm{~nm}$ and is proportional to the concentration of bilirubin. For total bilirubin, the reaction is accelerated by caffeine reagent. The readings for total bilirubin are taken after 5 min of incubation.

\section{Specimen-Serum Sample}

Procedure a. Bichromatic method.

Sample 50-Ill.

Solutionl-100.

Solution $3-1.0 \mathrm{ml}$.

\section{Estimation of Aspartate Aminotransferase Kit}

Method-RAICHEM diagnostics.

Reagent 2-Oxoglutarate.

L-Aspartate.

Lactate dehydrogenase.

Malate dehydrogenase.

NADH, buffers, stabilizers.

\section{Principle}

AST catalyzes the transfer of amino group from aspartate to oxoglutarate with formation of glutamate and oxaloacetate. Oxaloacetate is reduced to malate dehydrogenase. In this same reaction an equivalent amount of NADH is oxidized to NAD.

The resultant decrease in absorbance at $340 \mathrm{~nm}$ is followed spectrophotometrically and is directly proportional to activity of AST in serum.

\section{Specimen}

Serum sample

\section{ESTIMATION OF PLATELET COUNT \\ Method}

Direct Method, Rees- Ecker Method.

\section{Apparatus}

Compound Microscope.

RBC Pipette.

Neubauer's Chamber with coverslip.

Petridish, Moist filter paper.

Reagent-Rees-Ecker Fluid.

\section{Composition}

Sodium citrate-3.8gm.

Prevents coagulation.

Preserves RBC.

Provides the necessary low specific.

\section{Formalin-Acts as Fixative}

Brilliant cresyl blue-0.1gm.

Distilled Water-100ml.

\section{Principle}

Blood is diluted with a solution of brilliant cresyl blue, which stains the platelets as light blue. The diluent also prevents coagulation. RBC are not lysed. Platelets are counted by hemocytometry.

\section{Procedure}

Diluting fluid is taken upto 0.5 in RBC Pipette. Blood is drawn now, so that diluent reaches the mark 1.0. Again the diluting fluid is taken upto the 101. This gives dilution of 1 in 200 .

\section{Data Analysis}

All the data was tabulated and statistical analysis was done. The data was expressed as mean \pm standard deviation. Probability values-' $\mathrm{P}$ ' values was derived from analysis of variants. ' $P$ ' value less than 0.05 was considered statistically significant. The results were then interpreted and tabulated.

\begin{tabular}{|c|c|c|c|c|c|}
\hline \multirow{2}{*}{$\begin{array}{l}\text { Study } \\
\text { Group }\end{array}$} & \multicolumn{2}{|c|}{$\begin{array}{l}\text { No. of Cases } \\
\text { With }\end{array}$} & \multirow{2}{*}{ Mean } & \multirow{2}{*}{$\begin{array}{l}\text { Standard } \\
\text { Deviation }\end{array}$} & \multirow{2}{*}{$\begin{array}{c}P \\
\text { Value }\end{array}$} \\
\hline & Elevated & $\begin{array}{c}\text { Not } \\
\text { Elevated }\end{array}$ & & & \\
\hline $\begin{array}{l}\text { Mild PIH } \\
n=30\end{array}$ & 0 & 30 & 0.644828 & 0.190086835 & 0.823 \\
\hline $\begin{array}{c}\text { Pre- } \\
\text { eclampsia } \\
n=30\end{array}$ & 8 & 22 & 0.96333 & 0.359665964 & 0.09 \\
\hline $\begin{array}{c}\text { Eclampsia } \\
n=30\end{array}$ & 12 & 18 & 1.1 & 0.557837132 & $<0.001$ \\
\hline
\end{tabular}

Table 1: Shows in mild PIH group, bilirubin was not elevated with mean $0.64+0.8$. In pre-eclamptic group, bilirubin was elevated in 8 members (26\%) with mean $0.96+0.3$. In eclamptic group bilirubin was elevated in 12 members (40\%) with mean $1.1+0.5$. ' $\mathrm{P}$ ' value $(\mathrm{p}<0.001)$ shows significant elevation of bilirubin in eclamptic group.

\begin{tabular}{|c|c|c|c|c|c|}
\hline \multirow{2}{*}{$\begin{array}{l}\text { Study } \\
\text { Group }\end{array}$} & \multicolumn{2}{|c|}{ No. of Cases With } & \multirow{2}{*}{ Mean } & \multirow{2}{*}{$\begin{array}{l}\text { Standard } \\
\text { Deviation }\end{array}$} & \multirow{2}{*}{ P Value } \\
\hline & Elevated & $\begin{array}{c}\text { Not } \\
\text { Elevated }\end{array}$ & & & \\
\hline $\begin{array}{c}\text { Mild } \\
\text { PIH } \\
n=30\end{array}$ & 3 & 27 & 19.93333 & 3.580920064 & 0.92 \\
\hline $\begin{array}{c}\text { Pre- } \\
\text { eclamps } \\
\text { ia } n=30\end{array}$ & 14 & 16 & 33.66453 & 10.4171074 & $<0.001$ \\
\hline $\begin{array}{c}\text { Eclamps } \\
\text { ia } n=30\end{array}$ & 17 & 13 & 43.1 & 21.04568102 & $<0.0001$ \\
\hline \multicolumn{6}{|c|}{$\begin{array}{l}\text { Table 2: Comparison of Aspartate Transaminase } \\
\text { in Mild PIH, Pre-Eclampsia and Eclampsia }\end{array}$} \\
\hline
\end{tabular}

Table 2: Shows in mild PIH group Aspartate transminase was elevated in 3 members (10\%) with mean $19.9 \pm 3.5$. In pre-eclampsia AST was elevated in 14 members (46\%) with mean 33.6+10.4. In eclampsia AST was elevated in 17 members (56\%) with mean 43.1 \pm 21.0 . Mean values shows gradual increase of AST from mild PIH to eclampsia. "P" value shows significant elevation of AST in pre-eclampsia and eclampsia. 


\begin{tabular}{|c|c|c|c|c|c|}
\hline \multirow{2}{*}{$\begin{array}{c}\text { Study } \\
\text { Group }\end{array}$} & No. of Cases With & Mean & $\begin{array}{c}\text { Standard } \\
\text { Deviation }\end{array}$ & P Value \\
\cline { 2 - 5 } & Elevated & $\begin{array}{c}\text { Not } \\
\text { Elevated }\end{array}$ & Menn \\
\hline $\begin{array}{c}\text { Mild PIH } \\
\text { n=30 }\end{array}$ & 2 & 28 & 21.4 & 6.060613375 & 0.98 \\
\hline $\begin{array}{c}\text { Pre- } \\
\text { eclampsia } \\
\text { n=30 }\end{array}$ & 16 & 14 & 51.1 & 25.10440269 & $<0.001$ \\
\hline $\begin{array}{c}\text { Eclampsia } \\
\text { n=30 }\end{array}$ & 21 & 9 & 71.2 & 38.30044566 & $<0.0001$ \\
\hline \multicolumn{7}{|c|}{ Table 3: Comparison of Alanine Transaminase } \\
In Mild PIH, Pre-Eclampsia and Eclampsia \\
\hline
\end{tabular}

Table 3: Shows in mild PIH, ALT was elevated in 2 members $(6 \%)$ with mean $21.4+6.06$. In pre-eclampsia, ALT was elevated in 16 members (53\%) with mean 51.1+25.1. In eclampsia, ALT was elevated in 21 members (69\%) with mean 71.2+38.3. Mean values show gradual increase of ALT from mild PIH to eclampsia. "P" value shows significant elevation of ALT in pre-eclampsia and eclampsia.

\section{DISCUSSION}

Hypertensive disorders complicating pregnancies are common and form one of the deadly triad along with infection and haemorrhage that contributes greatly to maternal morbidity and mortality.

Platelet count and liver function tests get deranged in pre-eclampsia and eclampsia, which can serve as predictors of degrading PIH.

In the present study, LFT and platelet count were estimated. The mean value for each parameter is considered for analysis. The reliable and feasible parameters were considered for interpretation.

\section{Platelet count. \\ 2. Serum bilirubin. \\ 3. AST. \\ 4. ALT. \\ 5. ALP.}

The parameters chosen are:

In the present study, $77 \%$ of study group were observed between the age group of 18-25 years with gestational with age of mean 36.3 weeks. There were 52 primigravida and 38 multigravida of the total 90 study group.

\section{PLATELET COUNT}

In the present study it was observed that the mean value of platelet count was found to be $2.12 \pm 0.5$ in mild PIH group, $1.36 \pm 0.35$ in pre-eclamptic group, and $0.96 \pm 0.19$ in eclamptic group. There was gradual reduction of platelet count with increase in severity of PIH. This indicated thrombocytopenia is directly proportional to severity of PIH. The resulting thrombocytopenia is due to platelet activation, aggregation and consumption.

In a clinical trial conducted by Mohapatra and his associates observed that there is inverse relationship between the severity of PIH and platelet count. Platelet count was found to be $2.23 \pm 0.19$ in mild PIH, $1.82 \pm 0.45$ in pre-eclampsia and $1.21 \pm 0.49$ in eclampsia.
PLATELET ESTIMATION-MEAN VALUES (Lakhs/cumm)

\begin{tabular}{|c|c|c|c|c|}
\hline & $\begin{array}{c}\text { Present } \\
\text { Study }\end{array}$ & Mohapatra & Vrunda & $\begin{array}{c}\text { Kulka } \\
\text { rni }\end{array}$ \\
\hline Mild PIH & 2.12 & 2.23 & 2 & 1.8 \\
\hline $\begin{array}{c}\text { Pre- } \\
\text { eclampsia }\end{array}$ & 1.36 & 1.82 & 1.4 & 1.19 \\
\hline Eclampsia & 0.96 & 1.21 & 1.3 & 1.18 \\
\hline
\end{tabular}

\section{HEPATIC TRANSAMINASES-AST AND ALT}

It has been observed that the mean value for AST and ALT has been progressively increasing with increase in severity of PIH.

In mild PIH AST was elevated in $10 \%$ with mean 19.9 \pm 3.5 , ALT was elevated in $6 \%$ with mean $21.4 \pm 6.06$. In pre-eclampsia AST was found to be elevated in $46 \%$ with mean 33.6 \pm 10.4 , ALT elevated in $53 \%$ with mean $51.1 \pm 25$.1. In eclampsia AST elevated in $56 \%$ with mean $43.1 \pm 21$. ALT elevated in $69 \%$ with mean $71.2 \pm 8.3$. 'pet value showed significant elevation in pre-eclamptic and eclamptic group indicating the liver enzymes elevate with increase in severity of PIH.

The elevated liver enzymes are thought to be secondary to obstruction of hepatic blood flow by fibrin deposits in the sinusoid. This obstruction leads to periportal necrosis and in severe cases intrahepatic haemorrhage and subcapsular haematoma formation.

In a clinical trial conducted by Seymour.(2) including 85 patients with PIH, AST, ALT were elevated in 54\% of patients with pre-eclampsia, whereas in cases of gestational hypertension they were raised only in $14 \%$ of cases.

He pointed out that patients with abnormal liver function tests had bad maternal and fetal outcomes.

In another study conducted by Ayala LC, Maqueo et al.(3) serum transaminases were significantly elevated in $60 \%$ of 84 pre-eclamptic women. The levels of ALT raised to a greater degree than levels of AST. Similar observations were made by the Pritchard and Colleagues.(4) about serum hepatic transaminases, which were significantly elevated in preeclampsia and eclampsia.

In a similar study conducted by Makuyana in Liver and Kidney Function Tests in normal and pre-eclamptic gestation, the activity of AST $(\mathrm{P}=0.001)$ was significantly elevated in preeclamptic and eclamptic women.

\section{ALKALINE PHOSPHATASE}

In the present study, it was observed that ALP was elevated in $13 \%$ in mild PIH with mean 151.6 \pm 19.3 . In pre-eclampsia it was elevated in $56 \%$ with mean $196 \pm 41.2$ and in eclampsia it was elevated in $70 \%$ with mean $217.1 \pm 31.5$. ALP shows significant elevation with increase in severity of PIH $(\mathrm{P}<0.0001)$.Similar observations made by the Makunya Group, suggesting activity of ALP enzyme was significantly elevated in pre-eclamptic and eclamptic women $(\mathrm{P}<0.0001)$.

\section{SERUM BILIRUBIN}

With reference to serum bilirubin, it was not elevated in mild PIH group. In pre-eclampsia, it was elevated in $26 \%$ with mean $0.96 \pm 0.35$. 
In eclampsia, it was elevated in $33 \%$ with mean $1.1 \pm 0.5$. "PH" value shows significant elevation only in eclamptic group. It was observed that bilirubin does not show significant changes except in eclamptic group.

In the study conducted by Makunya, similar observation was made where bilirubin did not show any significant elevation in pre-eclamptic and eclamptic group suggesting that bilirubin levels does not alter much with increase in severity of PIH.

\section{SUMMARY AND CONCLUSIONS}

The present study was undertaken to evaluate the changes of Liver function tests and platelet count in different grades of $\mathrm{PIH}$ women. The study group included $90 \mathrm{PIH}$ women divided into 3 groups based on the severity of PIH into 30 mild PIH, 30 pre-eclampsia and 30 eclampsia. The LFT parameters and platelet count were estimated. Data was analysed by statistical method and the following conclusions are drawn:

- Platelet count was significantly reduced in pre-eclampsia and eclampsia. There is inverse relationship between the platelet count and severity of PIH.
- In liver function tests, AST, ALT and ALP were significantly elevated in pre-eclampsia and eclampsia suggesting elevation of these enzymes occurs with increasing severity of PIH. Bilirubin does not get much altered.

- LFT parameters like AST, ALT, ALP and Platelet estimation can be taken as an early interpretation for assessment of severity of PIH, so that early measures are taken to prevent the maternal and fetal complications.

\section{BIBLIOGRAPHY}

1. Brennard. Hypertension in pregnancy ACOG 1996;219:1-8.

2. Seymour CA, Chadwick VS. Liver and gastrointestinal function in pregnancy post graduate Med J 1979;55:343352.

3. Ayala LC, Maqueo, Mancilla-Jimenez R. Hepatic fibrinogen deposits in pre-eclampsia NEngl J Med 1976;295:578.

4. Robert JM, Cooper DW, Pathogenesis and genetics of preeclampsia Lancet 2001;357;53-6. 